Looking heteronormatively good! Combining story completion with Bitstrips to explore understandings of sexuality and appearance

\title{
Author and affiliations
}

Nikki Hayfield, Senior Lecturer in Social Psychology, University of the West of England (UWE), Bristol

Matthew Wood ${ }^{1}$, University of the West of England (UWE), Bristol

\section{Corresponding author:}

Dr Nikki Hayfield, Department of Health and Social Sciences, University of the West of England (UWE), Frenchay Campus, Bristol, BS16 1QY

Email: Nikki2.Hayfield@uwe.ac.uk Telephone: +44 (0)117 3282139

\section{About the authors:}

Nikki Hayfield is a Senior Lecturer in Social Psychology in the Department of Health and Social Sciences, at the University of the West of England (UWE), Bristol. Nikki's research interests are in sexualities, marginalised identities, relationships, and alternative forms of family. Nikki has published journal papers and book chapters on a range of topics including qualitative methodologies and bisexual identities and marginalisation.

Matt Wood is a PhD student in Digital Civics at Open Lab, Newcastle University. He completed his BSc in Psychology and his MSc in Health Psychology at the University of the West of England (UWE), Bristol. Matt's research interests are around the interception of digital technology and human sexuality, and he has commitments to innovative and visual qualitative methods.

\footnotetext{
${ }^{1}$ Matthew Wood is currently a PhD student in Digital Civics at Newcastle University, Open Lab, School of Computing, 1 Science Square, Science Central, Newcastle upon Tyne, NE4 5TG
} 


\begin{abstract}
:
This study sought to develop knowledge about understandings of bisexual, lesbian, and heterosexual women's appearance, by using a story completion task combined with an innovative visual methodology. Fifty-four (mainly female) participants were randomly assigned to complete a story stem about a fictional bisexual, lesbian, or heterosexual character, and then asked to build a Bitstrips online avatar of this character. Our social constructionist thematic analysis identified that 'looking good' was a common feature of the stories and that this was understood in largely heteronormative terms. This imperative was also clear in the stories of the date, which typically relied on traditional notions of gender and heterosexuality. Finally, individuality and authenticity were rewarded in participants' stories, yet this was simultaneously constrained by the (dominant) heteronormative narrative. We conclude that combining story completion with this innovative visual method enabled deeper insights into heteronormative representations of appearance, dating, and relationships than a textual method alone.
\end{abstract}

Keywords: Adornment; avatars; bisexual; gay; lesbian; heterosexual; innovative methods; sexualities; thematic analysis; virtual characters; visual analysis 
Visual identity intercepts with sexual identity and a rapidly changing culture means that there are a range of novel ways in which these can be managed and researched. In this study, we combined two innovative qualitative methods - story completion (Kitzinger \& Powell, 1995) and Bitstrips online avatars - to investigate contemporary constructions of bisexual, lesbian, and heterosexual looks and looking within the context of a (first) date. This methodological combination proved to be an effective way of generating data; the data were dominated by heteronormative appearance and dating norms, seemingly (almost) regardless of sexuality.

\section{The recognition of sexuality through appearance}

Dress and appearance is a meaningful aspect of our identities (Brennan, 2011; Clarke \& Turner, 2007; Hayfield, Clarke, Halliwell \& Malson, 2013). Appearance styles are often part and parcel of subcultures (e.g., hippy; Goth), hence shared appearance can signal our membership of particular identity groups (Polhemus, 2010). Visual identity has been of particular significance for lesbians and gay men who can embody, express, and communicate their identity through shared appearance norms (Hutson, 2010; Krakauer \& Rose, 2002). Communicating identity to others can enable 'standing out' from those identities to which we do not subscribe and 'fitting in' with those with which we do associate (Hutson, 2010: 213). This ability to recognise - and be recognised by - other lesbians and gay men has historically been critical in the creation of shared communities. This was particularly important when homosexuality was illegal and homophobia meant that lesbians and gay men were pathologized, but shared communities remain potentially safe spaces away from voyeuristic or homophobic gaze (Hutson, 2010; Krakauer \& Rose, 2002). Physical shared spaces, such as the 'gay scene', are where appearance norms around sexual identity are most readily recognised and regulated by others. In these spaces, dressing appropriately serves as a signal of shared identity and appearance becomes an indicator of membership of the group, hence of authenticity and belonging within the shared space (Clarke \& Smith, 2015; Clarke \& Turner, 2007; Eves, 2004; Hutson, 2010; Rothblum, 1994).

The most documented and recognised lesbian and gay 'looks' have traditionally been masculine/butch lesbians and effeminate gay men (Clarke \& Turner, 2007; Clarke \& Smith, 2015). However, within contemporary Western culture there are a diverse range of everchanging visual identities (Eves, 2004; Hutson, 2010). These can be created through nuanced clothing choices, piercings, tattoos, and hairstyles (Clarke \& Turner, 2007; Hutson, 2010). Lesbian and gay visual identities can also vary according to intersections of age, ethnicity, and social class (Rothblum, 1994; Taylor, 2007; 2008). Most recently, researchers have reflected on whether lesbian and gay appearance norms may be becoming less distinctive than they once were (Clarke \& Spence, 2013; Clarke \& Smith, 2015; Huxley, Clarke \& Halliwell, 2013). This has been attributed to the mainstreaming of tattoos and piercings (Huxley, Clarke \& Halliwell, 2013), alongside an increase in (heterosexual) metrosexual men who invest in styling and grooming in ways more commonly associated with gay men, to the extent that these practices may now be somewhat normative (Casanova, Wetzel \& Speice, 2016; Clarke \& Smith, 2015). This mainstreaming of lesbian and gay looks could be related to social and legal changes which have improved equality and promoted the acceptance of lesbian, gay and bisexual (LGB) identities (Huxley, Clarke \& Halliwell, 2013). In turn, this may mean that lesbian and gay appearance is less identifiable to others than it once was (Clarke \& Spence, 2013; Huxley, Clarke \& Halliwell, 2013). 
Bisexuality is often referred to as invisible and scholars have highlighted that bisexual people have been overlooked or marginalized both within academia and the wider culture (Barker \& Langdridge, 2008; Monro, 2015). There are seemingly no known distinctive bisexual visual identities and bisexual people may lack a recognisable 'look' or looks. Instead, bisexual people may only be able to 'borrow from' lesbian and gay appearance norms, or adopt androgynous or 'alternative' and 'funky' appearances (e.g., Goth and hippy) (Clarke \& Spence, 2013; Clarke \& Turner, 2007; Hayfield et al., 2013; Huxley, Clarke \& Halliwell, 2013). Therefore, bisexuality seems unlikely to be recognised through dress and appearance, even by other bisexuals (Hayfield et al., 2013).

Minimal research has specifically investigated whether heterosexual people recognise sexuality through dress and appearance. During the 1970s/1980s, researchers seeking to explore homophobia asked heterosexual participants to assess sexuality from photographs or images. Overall, masculinity was associated with lesbians and femininity with gay men. Images rated as less attractive than others were most likely to be perceived as lesbian or gay, particularly by those with 'homophobic attitudes' (see, Clarke, Hayfield \& Huxley, 2012; Clarke \& Smith, 2015). Indeed, heterosexual recognition of lesbian and gay identities has traditionally been associated with negative consequences including staring, verbal and/or physical abuse, and discrimination (Eves, 2004). Hayfield's (2013) survey research identified that UK students (most of whom were heterosexual) were unable to identify any distinctive bisexual appearance norms (although some described 'alternative' bisexual looks), but they were able to describe heterosexual, lesbian, and gay appearance norms. Lesbians were described as butch, and gay men as effeminate. However, participants dismissed their descriptions as 'stereotypes' perhaps to avoid positioning themselves as subscribing to stereotypes or as prejudiced.

\section{Researching appearance using story completion and visual methods}

Story completion tasks (SCTs), where participants 'tell a story' rather than presenting their own 'views' (see INTRO), offered a useful tool to explore people's understandings of sexuality and appearance, without participants having to 'take ownership' of their response to the scenario (Clarke et al., 2017). Within the context of the Story Completion Research Group (see Clarke et al., 2018), we wanted to explore what using visual methodologycould add to the potential for SCTs to generate rich data. Few researchers who have explored sexuality and appearance have drawn on visual methods (for exceptions, see Hayfield, 2011; Holliday, 1999). This may be because within psychology, written and spoken text has tended to be privileged over visual tools (Frith, Riley, Archer \& Gleeson, 2005; Reavey, 2010). However, visual methodology logically corresponds with the exploration of visual identities. We anticipated that SCTs combined with a visual element would be ideally suited to explore our research question which was what are people's understandings of cultural norms of bisexual, lesbian, and heterosexual women's appearance?

Visual approaches can enable researchers to explore verbal data alongside the visual to enrich (and disrupt) participants' accounts (Frith et al. 2005). Some psychologists have utilised photographs, while others have used scrapbooks, diaries, paintings, and drawings to explore various research topics (e.g., Frith et al., 2005; Hurworth, 2004). Most recently, contemporary representations of sexuality and identity have been explored through participants' video diaries and social media to enhance interpretations of how identities are 
managed and maintained (Goodings \& Brown, 2011; Pini \& Walkerdine, 2011). With the increased popularity of online avatar software at the time of the study, we saw an opportunity to combine an innovative digital visual element with the written story to see whether, or how, inviting participants to generate a representation of the character in their stories could complement SCTs.

The online platform Bitstrips rapidly gained popularity on the Internet in the early 2010 s as a way to digitally create a virtual cartoon character or 'avatar' (with the option to generate short comic-strip narratives). Virtual worlds have been said to represent new sites in which to represent or perform identity, particularly in more established spaces such as second life, where avatars may have a co-evolving relationship with their creator/occupier (Meadows, 2008). New technological expressions of embodiment are becoming more commonplace (Reavey, 2011), and avatars may represent a complex relationship between 'real' and 'virtual' identities (Boellstorff, 2008), particularly in how various aspects of identity are played out (Nakamura, 2002). Some scholars met this new medium with enthusiasm for the opportunities it presented within educational contexts (Nisa \& Al-Hafizh, 2014; Wertz, 2014), but despite calls for researchers to willingly engage with how people use new technologies (Reavey, 2011), Bitstrips was seemingly not taken up by psychologists.

While we were designing this research, Bitstrips' was particularly popular on Facebook, and the platform, with its relative ease of creating virtual cartoon characters, seemed ideal for our purpose. We were interested in how sexuality and appearance might be represented, so we asked participants to create an online Bitstrips avatar of their character after completing the SCT. Participants were therefore able to complete the study entirely online; their written response in Qualtrics and the visual element in Bitstrips.

\section{Recruitment and procedure}

Ethical approval was granted by the Faculty Research Ethics Committee at the University of the West of England (UWE). Participants were mainly UWE undergraduate students recruited using an online participant pool and awarded credit towards a research assignment. We also advertised the study via our own social networks (e.g., Facebook). When participants expressed an interest, they were directed to Qualtrics online survey software and instructed to read the information sheet which provided details about the researchers, participation, and the study. Participants created an anonymous identifier and provided their fully informed consent online.

We designed an SCT with a story stem involving a date where appearance was clearly a factor, but in which participants were not asked directly about the topic; instead they were asked to create a visual representation of the character's appearance via Bitstrips. Qualtrics was set-up to randomly assign participants to a bisexual, lesbian, or heterosexual version of the following stem:

Jess is a 21-year-old (bisexual/lesbian/heterosexual) woman. She has recently met someone, and they have arranged to go on a date.

The stem was left deliberately ambiguous (e.g., who the character has met and how; see Clarke et al., 2017) although the implication was that this was a first date. The stem was followed by instructions to tell a story about the run up to the date, how the character 
prepared for the date, how the date went, and what happened next. Participants were advised to write as much, and as far into the future, as they would like. We then asked participants to create a visual image of the character using Bitstrips, and provided detailed instructions, including to copy and paste the image into a Microsoft Word document and email to the researchers. Participants answered demographic questions so that the sample could be situated.

\section{Participants}

There were 54 participants, mainly female ( 43 females; 10 males; 1 did not respond) and heterosexual (48 heterosexual; 5 bisexual; 1 asexual). The age range was 18-44 years $(M=23)$; most were $18-21$ years with only 10 participants $25+$ years. Participants were mainly middle (28), or working class (18), with the remainder no-class (5), or unsure (3). Most participants were White (44), with 7 Black (1 specified Black British and 1 Black African), 1 White/Black Caribbean, 1 Asian Muslim, and 1 Chinese. Thirty-six reported being in a relationship (e.g. 'seeing someone' to 'living with a partner' or 'married'). Forty-eight were students ( 39 full-time; 9 part-time) and twenty-one were employed ( 6 full-time; 14 part-time; 1 freelance). After removing incomplete responses, there were twenty bisexual, fourteen heterosexual, and twenty lesbian stories. Fifteen participants did not complete the avatar requirement.

\section{Analysis}

We analysed the data within a social constructionist framework (Burr, 2003), as is common in SCT studies, particularly when researching gender and sexuality (Clarke, Braun \& Wooles, 2015; Frith, 2013; Kitzinger \& Powell, 1995). Most visual methods research has focused on personal narratives within an experiential framework where the visual is seen as a 'window to experience' (Pink, 2015). By contrast, our participants wrote stories and created fictional characters in response to a hypothetical scenario. We understood Bitstrip images as produced in accordance with dominant narratives and societal resources available to participants (Pink, 2015). We aimed to interrogate how these images reproduced social and cultural understandings and focused on the representations of sexuality and appearance that were generated through text and images.

Thematic analysis (Braun \& Clarke, 2006) was chosen to identify patterns in the textual data alongside Bitstrip images. When data collection ended we organised the data into three separate Microsoft Word documents (bisexual; lesbian; heterosexual) with the associated Bitstrip for each story. Familiarisation began during data collection when we read responses on Qualtrics and looked at Bitstrips images as we received them. We took a mainly inductive approach during familiarisation and coding, where we started with the data rather than approaching analysis with any particular codes or theories in mind. However, we were inevitably somewhat deductive due to our personal and academic backgrounds and associated awareness of LGB appearance norms, which we were able to identity (a lack of) within text and images. We independently read and re-read the data in conjunction with the images before discussing our impressions and moving to coding the data. We identified semantic codes at the surface of the data and latent codes at a deeper level and examined how data fitted together within each sexuality grouping and across the data corpus. We considered which codes were most prevalent and how these could be conceptually organised into themes, either by 'promoting' codes to themes, or collecting codes together 
into groups. We reviewed these themes, before defining and naming them; final analytic adjustments were made as we wrote-up our analysis.

\section{Results}

Overall, we found heterosexual appearance norms, characterized by chasing (unattainable) standards of heterosexual beauty, dominated textual and visual responses, while lesbian (or bisexual) appearance norms were recognised only to a limited extent. Gendered norms and heterotypical happy endings prevailed in these stories. While narratives of authenticity were sometimes a vehicle by which to challenge normative notions, careful negotiation was required; non-authenticity was often punished, as were departures too far from (gender and hetero) normative dating scripts.

\section{Looking (heteronormatively) good!}

An imperative of 'looking good' was a common feature of nearly all the stories, yet this was largely governed by heterosexual appearance norms. Female characters were consistently represented through traditionally (heterosexual) feminine attire, including dresses, long hair, and make-up (Gonzalez \& Spencer, 2015; Hayfield, 2013). This was common across the dataset, regardless of whether the character was bisexual, lesbian, or heterosexual. Alongside this, participants provided lengthy accounts of preparation rituals. Jess was described as shopping for clothes, bathing "in the glorious aromas of geranium rose and bergamot oils" (HO4, Black British, 41, story/avatar of a heterosexual character), shaving, attending to hair and make-up, and making careful and deliberated decisions about what to wear:

After dragging out half her closet she has finally
decided what she is going to wear, then the
tedious challenge of choosing shoes... This brings a
whole new dilemma to the situation, to wear
heels and possibly be significantly taller than her
date- just to achieve longer looking legs or just
wear cute flat shoes (B01, White female, 24,
story/avatar of a bisexual character).


Jess had a shower, shaved her legs, trimmed her other regions before moisturising everywhere (LO2, White female, 24, story/avatar of a lesbian character).

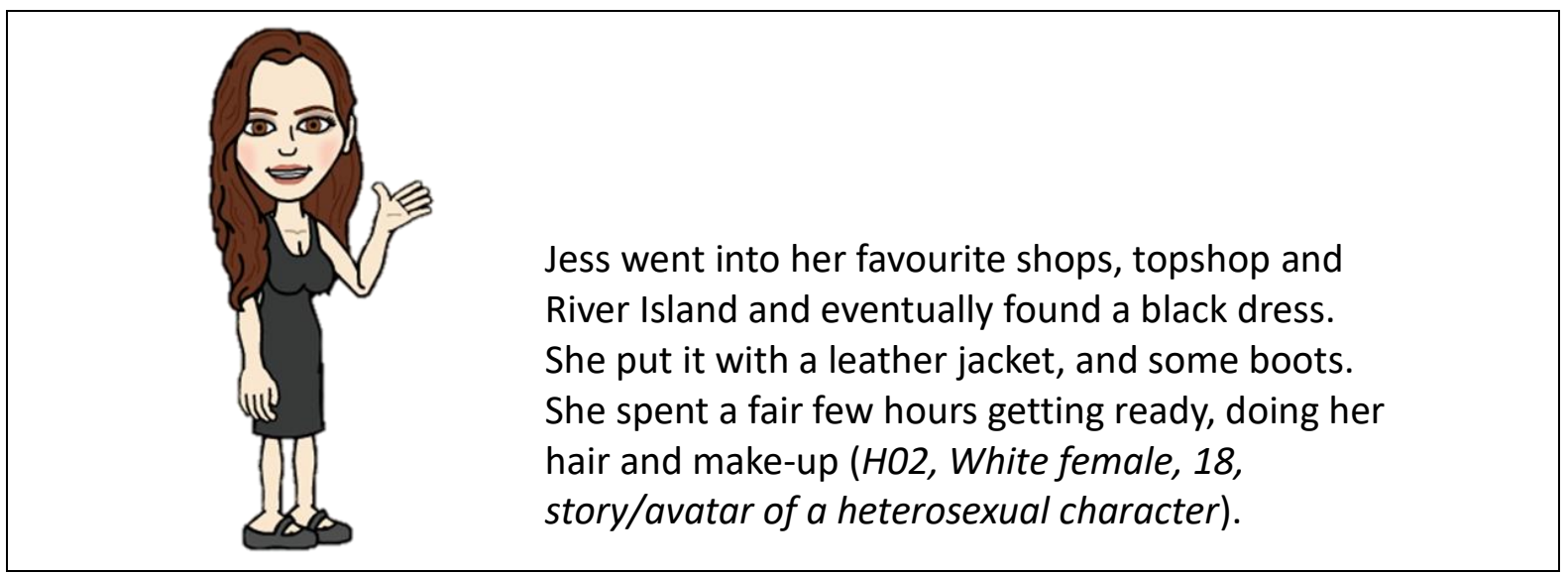

Jess's (intensive) preparation for her date, and in particular related accounts of 'angst', suggests managing appearance for others' approval as a (hetero)normative part of dating (Pickens \& Braun, 2018; Tolman, Davis \& Bowman, 2016). Managing a (heterosexual) 'look' was not always portrayed as pleasurable - the "tedious challenge" and "dilemma" of choosing shoes - but this was seemingly inherently necessary in preparation for a date. This imperative was identified regardless of Jess's sexuality. These appearance norms were also frequently characterised by portrayals of the character striving for perfection:

She spent hours on her hair to make sure that not
even a strand was out of place and her make-up
was inspired by Audrey Hepburn in Breakfast at
Tiffany's. She wanted to look pretty and chic. She
tried on every dress in her closet and none of
them seemed to go well with the look she was
aiming so desparately [sic.] for (LO1, Black female,
18, story/avatar of a lesbian character).




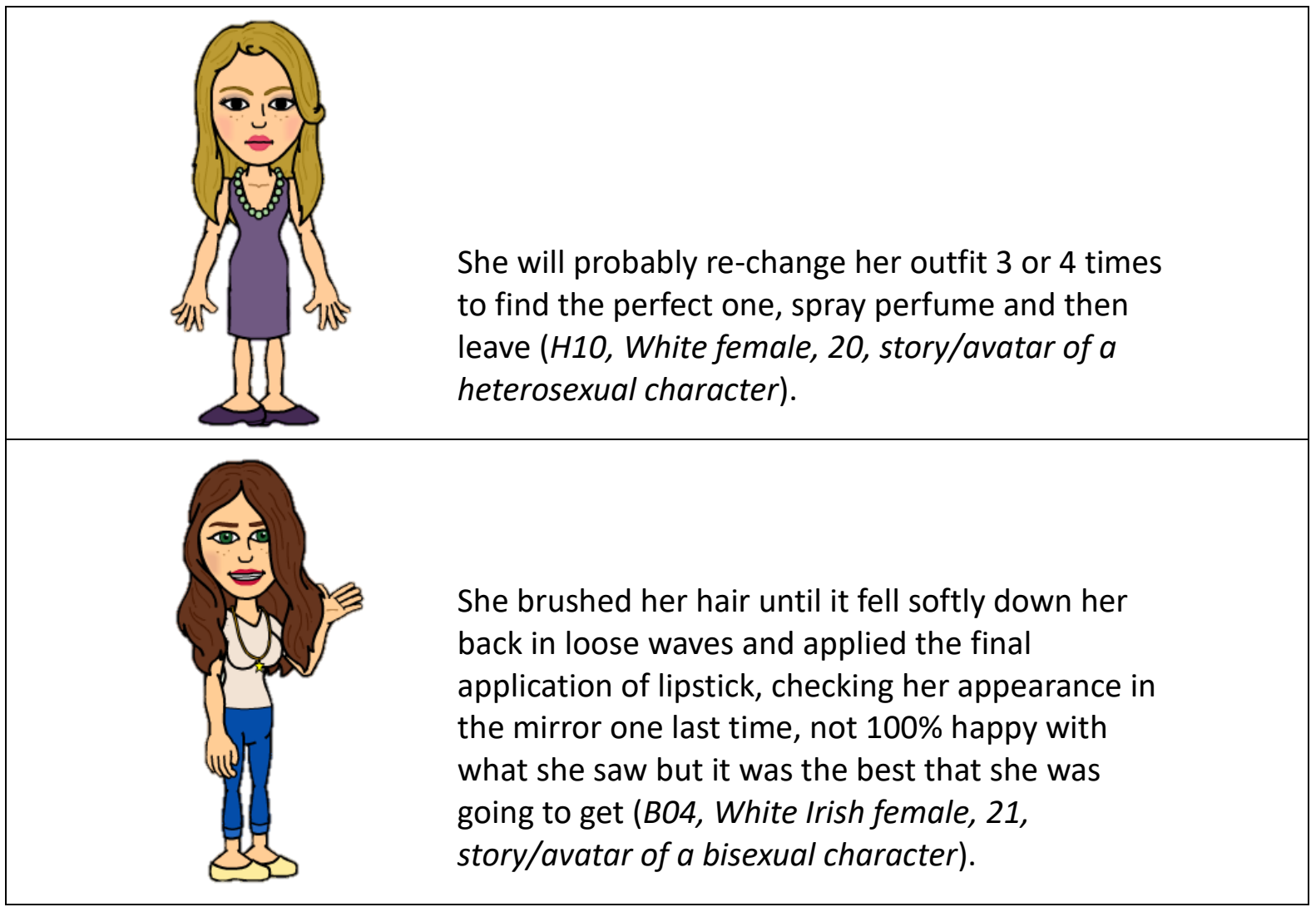

For L01, the "pretty and chic" look, inspired by the stereotypically beautiful "Audrey Hepburn", was "desperately" sought, whereas for H10 the 'perfect' outfit could only be decided upon through repeated clothing changes. Elsewhere, friends were consulted to confirm "the best possible choice" (HO8, White female, 20, story about a lesbian character). A perfection imperative was also apparent in B04 through a wariness that she hasn't reached the "highest standard', "but it was the best that she was going to get" (B04). The characters' tireless striving for an (unachievable) perfect appearance depicted in these stories links with (unattainable) flawless standards of beauty associated with heterosexuality (Pickens \& Braun, 2018).

It took several readings of the text to identify any (minimal) evidence of alternative accounts of appearance. Only five images portrayed the character with short hair, an indicator of how (heteronormatively) feminine the characters were (Gonzalez \& Spencer, 2015). Further, only two pictures clearly subscribed to what could be described as a 'lesbian look' with 'comfy shoes' and short hair (Clarke \& Turner, 2007). The written responses which accompanied these images also placed (somewhat) less emphasis on the perfect appearance: 
Jess's first dilemma was her appearance; Jess combed her short black hair, put on one coat of black mascara to emphasis her piercing blue eyes and smeared on some lip gloss. Then Jess was fretting about what to wear, so chose her old faithful jeans and tight white vest top (LO3, White female, 32, story/avatar of a lesbian character).

Although the 'dilemma' of appearance was present in L03's story, Jess's hair was short and combed, rather than styled, her final clothing decision guided by reliability ("old faithful jeans"), rather than perfection; in L20's story, appearance was not a dilemma:

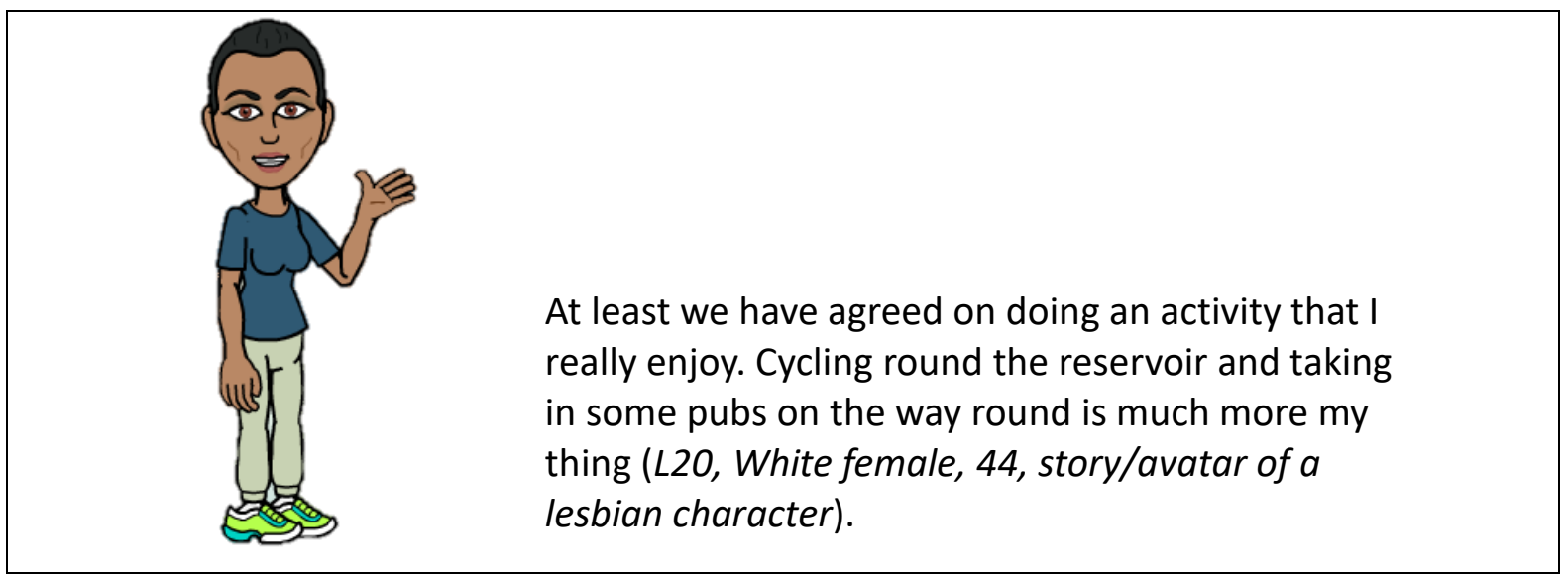

We suggest that lesbian appearance norms were being drawn upon here, despite a more prominent discourse of normative heterosexual appearance and (unattainable) appearance standards. However, there were no descriptions of lesbian or bisexual characters actively resisting feminine (heterosexual) appearance practices in the textual responses, despite lesbian and bisexual women potentially being less invested in norms like body hair removal and cosmetics than heterosexual women (Hayfield, Halliwell \& Clarke, 2017). Overall these participants provided relatively uniform accounts in which creating the perfect (heteronormatively feminine) appearance was constructed as an important aspect of preparing for a date, regardless of the character's sexuality.

\section{A traditionally (heterosexual) gendered life}

The stories of the characters and their dates often relied upon traditionally and heteronormatively gendered appearances, roles, and expectations. If Jess' date was mentioned, and was a woman, then her physical appearance was often described. Jess's date was "looking beautiful in a cute skater dress and heels" (B04, White Irish female, 21, story/avatar of a bisexual character), "much better looking in person compared to their picture" (B06, White female, 22, story/avatar of a bisexual character) and had "long wavy 
blonde hair glistening in the light" (LO3, White female, 32, story/avatar of a lesbian character). When on a date with a man, his appearance was rarely described, illustrative of appearance norms governing women more than men (see Frith \& Gleeson, 2004). However, this was not exclusively the case. Although participants were not asked to create a Bitstrip of Jess's date, a few did, mainly of male dates in the heterosexual scenario:

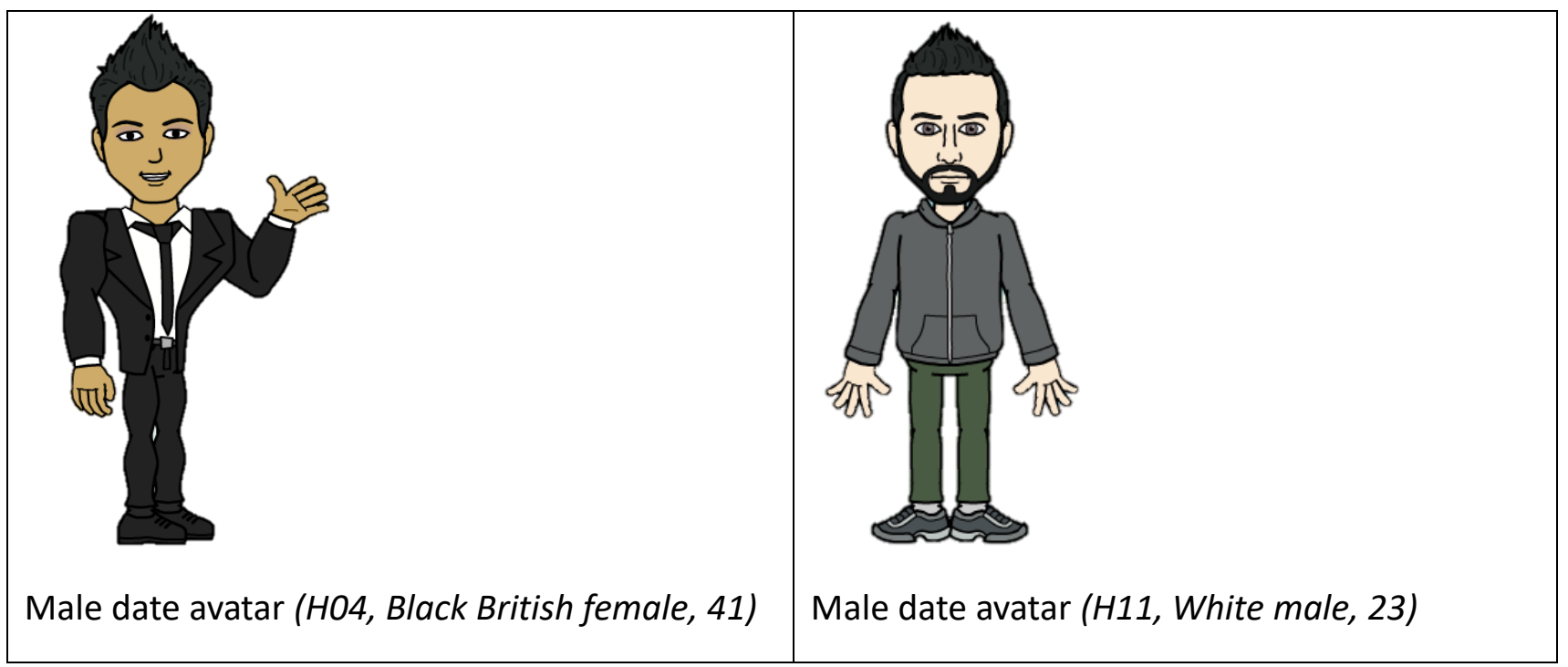

These were sometimes accompanied by a description: H04 described Jess's hypermasculinised male date in lavish detail. His hair was "short and styled in a way that enhanced his beautiful cheekbones and framed his face so perfectly" (Black British female, 41).These male avatars largely subscribed to contemporary masculine appearance standards, such as beards, a slender physique, and muscles. In this sense, there was some notion of the heterosexual metrosexual man (Clarke \& Smith, 2015; Casanova, Wetzel \& Speice, 2016) evident in depictions of the characters' dates.

Stories were also traditionally gendered when participants evoked heterosexual roles and expectations (Yancey \& Emerson, 2016), such as the danger of Jess "wear[ing] heels and possibly be[ing] significantly taller than her date" (B01, White female, 24, story/avatar of a bisexual character), or the protocols of who pays for dinner (Jaramillo-Sierra \& Allen, 2013; Lever, Frederick \& Hertz, 2015). In contrast, when Jess was on a date with a woman, she was sometimes said to feel "unsure about the 'rules' of girls dating girls" (B05, White British female, 28, story of a bisexual woman), and was often reported to be new to dating women. This portrayal of different 'rules' is interesting, given that LGB dating may differ from heterosexual conventions (Lamont, 2017). This may be indicative of the cultural availability of traditional heterosexual scripts versus the unimaginability of any alternative same-sex narratives.

We also engaged in 'vertical analysis' which focused on story structure and endings (Braun and Clarke, 2013). Traditional dating scripts are reported to largely revolve around the couple going for dinner and ending in the man kissing the woman goodnight (Laner \& Ventrone, 2000). The heterosexual stories were largely underpinned by gender stereotypes of the man mainly leading the date (Pickens \& Braun, 2018):

Jess and Mike met at a pub [then] went to have some food. Jess had a lovely time; Mike made her laugh a lot, and he was more handsome than she'd remembered. He 
offered her a lift home after dinner but she refused as she said she'd like the walk. They walked in the same direction for a little while, and when it came to time to part ways, Jess was pleased that he took the opportunity to kiss her (H05, White British female, 34, story/avatar of a heterosexual character)

Although we note that participants did sometimes rely less on a dominant leading character, lesbian and bisexual stories were broadly similar to heterosexual narratives:

Jess met her date in a restaurant in the early evening, they both quickly got into deep conversation that was only broken by the waiter taking their order [...] By the end of the night they really felt that they've "clicked". Jess and her date walk together to the taxi rank where there is an awkward moment before they kiss goodbye (LO7, White English male, 21, story about a lesbian character, no avatar)

Most stories progressed with the characters continuing to date, living together and having children (although in lesbian and bisexual narratives this was sometimes pets). Stories often clearly ended (heteronormatively) happily, regardless of the sexuality of the character:

A few years later they eventually bought a house together and bought another dog. When she was 27 years of age, after being together for roughly 6 years, they got married and shortly after she had a baby girl. They grew old together and retired and moved to Spain (H08, White female, 20, story about a lesbian character).

Jane and Ella continued to see each other, they became closer and closer until it was clear they were in love. Jane sold her London flat and they moved into a cute apartment by the Thames [...] One day they decided to take it to the next level. They drove to the nearest animal shelter and adopted a tiny black kitten, whom they named Bambi. A perfect addition to the household, endless entertainment, and their lovechild, as Ella would often joke (B07, White female, 20, story about a bisexual character).

Lesbians and gay men (and perhaps bisexual people) may be critical of, and subvert, heteronormative relationship practices (Lamont, 2017). This can include resisting gender norms (partly due to their lack of relevance in many LGB relationships), being nonmonogamous, and a range of non-heteronormative living and parenting arrangements (Kitzinger \& Coyle, 1995; Weeks, Heaphy \& Donovan, 2001). However, overall these participants presented relatively homogenous stories that most closely mirrored heterosexual notions of dating and long-term relationships.

\section{Imperatives of individuality and authenticity}

The happy endings, common across our data, were often underpinned by representations of individual and authentic 'selves'. These stories often contained some sense of individuality being maintained by Jess or her partner:

Carl's silverware ridden career continued for years to come, picking up all major honour captaining club (his beloved Arsenal) and country. He [...] cherished the normal relationship they shared and they lived many happy years. In retirement Carl went on to manage Arsenal to further success, retiring surprisingly early to spend 
time with family he had with Jess (B10, White male, 20, story/avatar/comic strip

about a bisexual character)

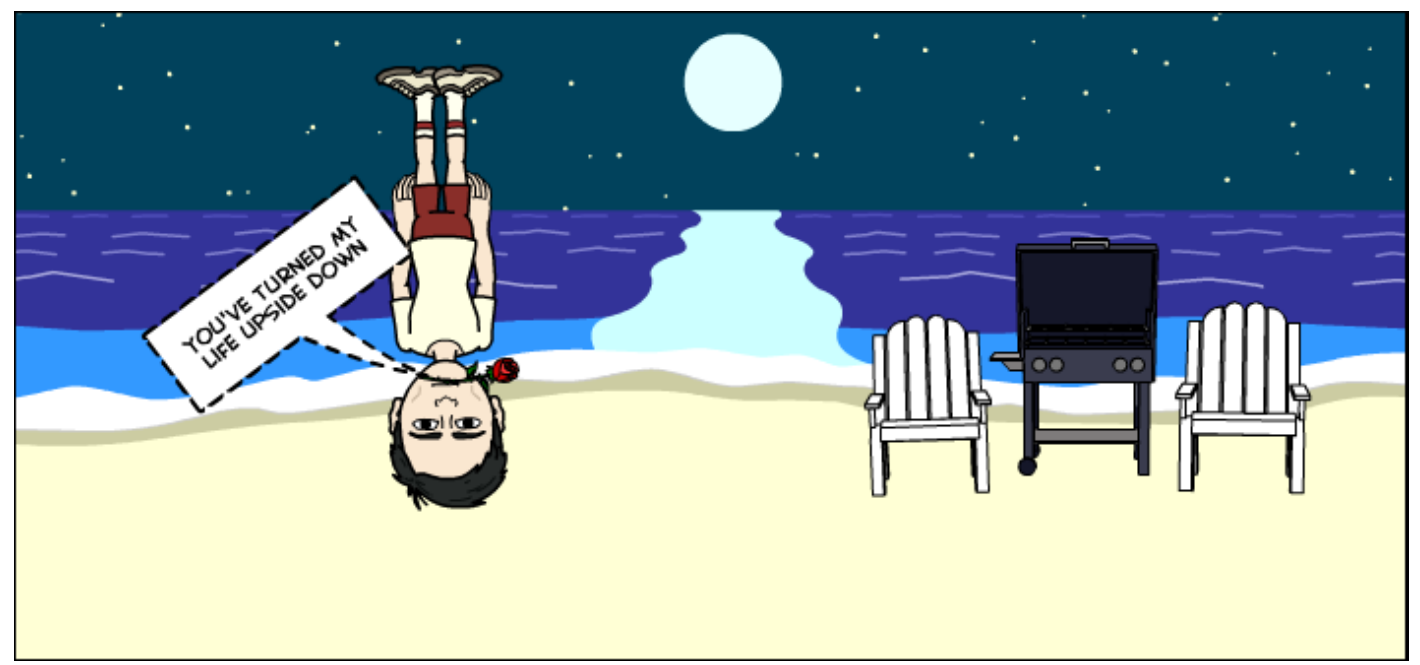

In the most visually striking depiction of our Bitstrips data, Carl's life is literally turned 'upside down'. Yet the story featured Jess embracing his focus on a successful career as manager of Arsenal football club - a commitment to a traditionally (authentically) masculine sport (Hayfield, 2013) - which culminated in a happy ending of family and early retirement.

When authenticity was exercised, it was often rewarded in a variety of different forms, which sometimes departed from a heterotypical narrative. Although traditional dating scripts were most common across our data, the story endings sometimes (especially about bisexual characters) provided a contrast to dominant heteronormativity through a narrative of a (successful) authentic individual:

When it was time to pay the bill, Matt insisted on
paying for everything. This made Jess angry as she
felt it was demeaning to her as well as chauvinistic
[...] she decided that men were not worth the
trouble after all [...] Jess became a successful
youtube feminist video maker who made
thousands from advertising every day (H14,
Chinese male, 20, story/avatar of heterosexual
character).

Before anything else, Jess was an artist. Not in the "brushes \& paints" kind of way - no, no. Rather more she preferred to make her life her art \& fill it with beauty whenever she could [...] so, irrespective of the brilliance of that night, with its gin-soaked, smoky kisses \& pretend-Parisian style [...] Jess knew there would be many more of them, with many more lovers (B03, White female, 32, story of a bisexual character, no avatar)

H14's story challenges gender roles, specifically the protocol of the man paying for dinner (Jaramillo-Sierra \& Allen, 2013; Lever, Frederick \& Hertz, 2015). Jess was illustrated with an 'alternative' appearance and is rewarded, non-heteronormatively, for her authenticity in 
following a (feminist) passion to be successful as a YouTube star. B03's story also directly challenged romantic and monogamous dating narratives. In remaining true to her individuality as an artist, Jess's happy ending revolved around not settling down, but rather the prospect of 'many more lovers', which perhaps draws on (sometimes negative) associations of bisexuality with multiple partners (Hayfield, Clarke \& Halliwell, 2013).

In contrast, when appearance practices were deemed to be inauthentic, the protagonist was often punished:

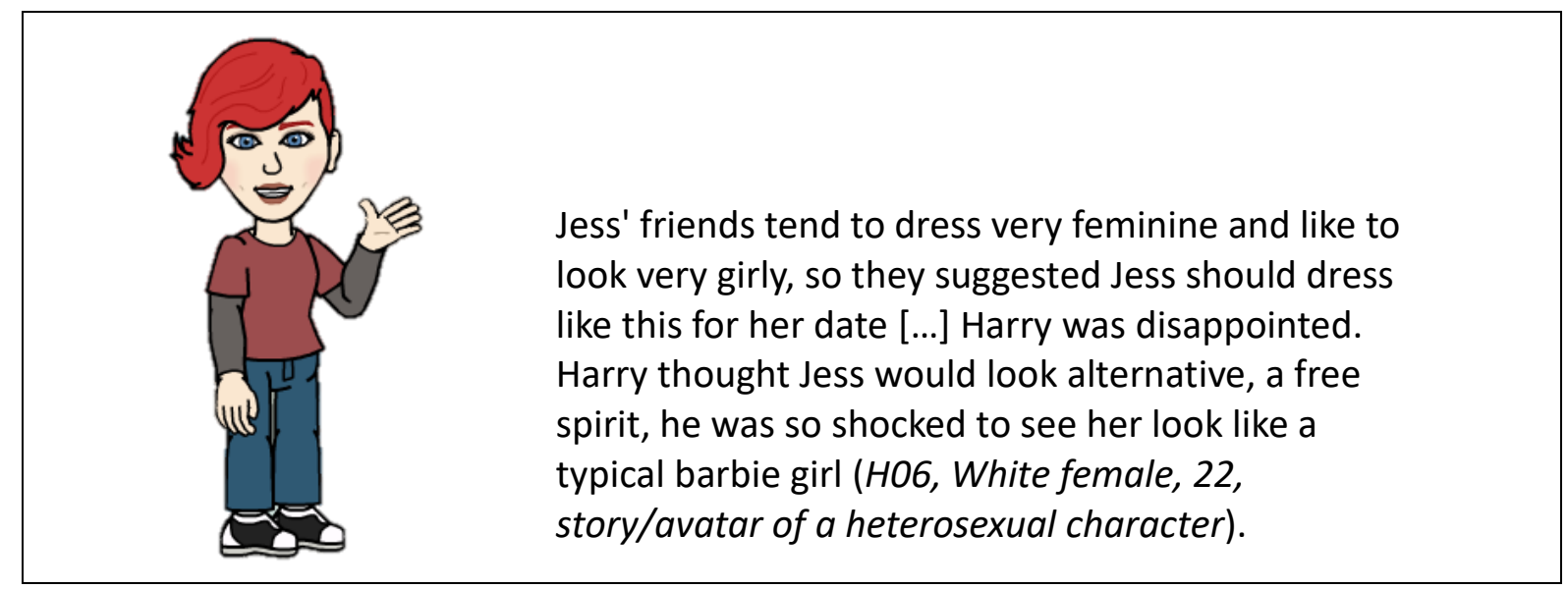

In H06's story, overly heterosexual appearance norms are characterised as inauthentic, her conformity for the date branded as "typical Barbie girl", and the character was ultimately punished for going against her better judgement.

Within the dating scenario we presented to participants, authenticity was typically rewarded, but only within certain parameters. When authenticity existed too far outside the boundaries of a heteronormative framework, there was a risk that the character would be punished or the date would become (heteronormatively) unsuccessful:

As much as jess wanted to meet again she realised
they was no spark, and the meeting would be just
as friends. Jess decided to tell them how she felt,
better to be honest then drag them along. Her
date however was not so gracious, and sent back
abuse [...] she got more letters and a friend told
her about a blog her date had made about her,
saying not so complementary [sic] things... so jess
returned home in fear (B06, White female, 22,
story/avatar of a bisexual character).


Her date became very arrogant and didn't like the ice skating or the magical ice kingdom Jess had booked for them. [...] They argued all the way home and separated going different ways as soon as they were back at the station (B18, White female, 18, story/avatar of a bisexual character).

B06's account was the only story in our sample where Jess proposed friendship rather than a relationship at the end of the date, challenging the traditional (heterosexual) dating scripts (Laner and Ventrone, 2000). However, instead of being rewarded for being authentic, in disrupting dating scripts Jess was punished with sustained abuse. Likewise, Jess taking her date to "the magical ice kingdom" arguably represents a date which contains individuality and an 'authentic self'. However, this non-traditional location exists outside the construct of a normative adult heterosexual date, almost childlike, which resulted in a (heteronormatively speaking) unhappy ending. In general, departures from heteronormative scripts were rarely rewarded, hence a danger of being 'too' authentic or 'too' individual, outside what appear to be fairly tightly regulated heteronormative norms (Pickens and Braun, 2018). When stories differed from traditional dating scripts, happy endings became jeopardised and being 'too' authentic represented a threat to heteronormative happy endings.

\section{Discussion and conclusions}

A key finding of this study is the minimal evidence of diversity across lesbian, bisexual, and heterosexual characters, in either textual or visual data. Our main conclusion is that the characters' appearance, appearance practices, dating, and relationships were all represented in predominantly heteronormative ways. We anticipated that SCTs might free participants from socially desirable responses in relation to appearance (Hayfield, 2013). Therefore, it was hoped that this study could offer additional insight into contemporary understandings of cultural norms around bisexual, heterosexual, and lesbian appearance. However, stories and images were overwhelmingly dominated by the notion that all women (regardless of sexuality) invest in traditional (unattainable) feminine beauty ideals (Pickens \& Braun, 2017). Only a few participants represented Bitstrips characters in ways which resonated with classic lesbian appearance norms such as short hair, comfortable shoes, and 'butch' looks (Clarke \& Turner, 2007). This indicates that these (mainly heterosexual) participants may not have had the cultural capital to reproduce 'lesbian looks'. The lack of diversity in bisexual appearance was unsurprising, given the cultural invisibility of bisexuality, hence there are few culturally recognised images of bisexual appearance for (heterosexual) participants to draw upon (Hayfield et al., 2013; Hayfield, Clarke \& Halliwell, 2014).

Overall, we conclude that heterosexual appearance norms dominated understandings of women's appearance. Our findings also link with the normalisation of lesbian, gay, bisexual, and queer identities within mainstream culture (see below), which could mean that specific 
looks associated with particular sexualities are diminishing and/or becoming less culturally accessible to those who are not 'in the know' (Clarke \& Spence, 2013, p.25; Huxley, Clarke \& Halliwell, 2013). In our SCT, the setting was implied to be a formal first date between two people, hence these understandings about the (re)production of appearance norms are context specific. SCT designs could be utilised with lesbian, gay, bisexual, trans and queer (LGBTQ+) participants who may have the different cultural knowledge, and the story set within specifically LGBTQ+ locations (e.g., stories revolving around a night out on the 'scene'), where appearance norms relating to sexuality have historically been most relevant, recognised, and regulated (e.g., Eves, 2004; Taylor, 2007; 2008).

Heteronormativity also dominated participants' accounts of dating and relationship practices. Participants' stories were notably similar regardless of the sexuality of the character and relied heavily on traditional (heterosexual) scripts of dating and relationships (Laner \& Ventrone, 2000). It was unusual for participants to provide any stories which disrupted these, or indicated that they had access to either the idea or reality of LGBTQ+ people 'doing' dating and relationships any differently from heterosexual people (Kitzinger \& Coyle, 1995; Lamont, 2017; Weeks, Heaphy \& Donovan, 2001). The uniformity across different versions of the story, and the punishment of characters who deviated from heterosexual norms, suggests participants' location within a culture of 'homonormalization' (Croce, 2015; Roseneil et al., 2013). The term homonormalization refers to lesbian and gay (and perhaps bisexual) identities becoming (to some extent) assimilated within mainstream heterosexual society. Scholars have been critical of normalisation, in part because assimilation limits the radical potential of LGBTQ+ identities to challenge traditional values and norms. Instead, particular forms of LGBTQ+ lives and relationships become 'tolerated', provided they are compatible with heterosexual norms (Croce, 2015; Roseneil et al., 2013). Empirical research could further develop our knowledge of the implications of homonormalization on understandings, and lived experiences, of LGBTQ+ appearances and identities.

\section{Reflections on combining story completion and Bitstrips images}

The few differences accorded to (mainly lesbian) sexuality were sometimes more readily apparent in images than in stories, indicating that our visual method added depth and richness to our data and analysis. Bitstrips fitted well with story completion, because the focus was on hypothetical characters and hypothetical scenarios. Writing a story and designing an image may have made the study novel and appealing. Story-writing and cartoon images are potentially fun and creative, and this was sometimes reflected in the responses. Bitstrips was a relatively resource-lite visual methodology and creating an online character meant there were few ethical difficulties (e.g., confidentiality and anonymity), unlike other forms of visual data (Frith et al., 2005). There may be value in communicating research findings via visual methods, and Bitstrips characters provided a novel and engaging way to present our results.

However, there were practical and methodological limitations. Nearly a third of participants did not complete an avatar. This may link to the detailed step-by-step guidance that participants were required to follow so that they could use Bitstrips without registering. We had to instruct participants on how to create, edit, and save a Bitstrips character. They then had to capture a screenshot of their image, paste it into Microsoft Word, and email the 
researchers. Participants may have found this cumbersome or challenging, especially for those using mobile devices or Mac computers. Future researchers engaging with online technologies need to consider these factors.

Similar to SCTs (Clarke et al., 2018), there are questions around what visual data represents and there remains a lack of guidance around visual analysis (Frith et al., 2005). It is difficult to consider Bitstrips as anything other than supplementary to the text, which highlights the dilemmas that researchers continue to face in the use of visual methods, regardless of what form they take (Gleeson, 2011). There has been also scepticism around the generic nature of avatars, in particular the lack of creativity Bitstrips offered users (Cimarusti, 2013).

Participants had some flexibility and could choose from a range of clothes, shoes, hair (length and styles), facial hair, and accessories (e.g., scarves, necklaces, and glasses). However, Bitstrips did not allow participants to portray subtle aspects of appearance (e.g., piercings, tattoos, or jewellery such as pride symbols) - precisely the nuanced features that can convey sexuality within the wider culture (Clarke \& Turner, 2007; Hutson, 2010, Huxley, Clarke \& Halliwell, 2013). The processes of avatar building are constantly evolving, however, and since our research, Bitstrips has become Bitmoji (www.bitmoji.com), which provides more advanced (but still limited) options. The purpose of Bitmoji has evolved in scope from fantasy contexts to focus on expressions of self-identity, particularly through new communication mediums such as Snapchat (www.snapchat.com), which is set to be a fruitful area for further exploration.

Our research captured a particular form of cartoon imaging that was popular at that time, but only lasted for a short period. However, in being mindful of how these technologies are evolving, and considering the cultural purposes around these new forms of digital visual expression, these mediums provide research opportunities. We argue that engaging with online visual methods alongside novel forms of data collection offers opportunities for both methodological innovation and increased knowledge and understanding of phenomena. Our overall finding was that heterosexuality dominated and this was evident in stories and Bitstrips images. Therefore, this study successfully combined SCTs with innovative visual methodology to further develop our understandings of (heteronormative) cultural norms of sexuality and appearance.

\section{References}

Barker, M \& Langdridge, D 2008, 'Bisexuality: Working with a silenced sexuality', Feminism \& Psychology, vol. 18, no. 3, pp. 389-394.

Braun, V \& Clarke, V 2006, 'Using thematic analysis in psychology' Qualitative Research in Psychology, vol. 3, no. 2, pp. 77-101.

Braun, V \& Clarke, V 2013, 'Successful qualitative research: A practical guide for beginners', Sage, London.

Brennan, S 2011 'Fashion and sexual identity, or why recognition matters' in J Wolfendale \& J Kennett (eds.) Fashion - philosophy for everyone: Thinking with style, Blackwell Publishing, Chichester, West Sussex, pp. 120-134.

Burr, V 2003, 'An introduction to social constructionism' London: Routledge 
Casanova, EMD, Wetzel, EE, \& Speice, TD 2016 'Looking at the label: White-collar men and the meanings of "metrosexual"'. Sexualities, vol. 19, no 1-2, pp. 64-82.

Cimarusti, N. 2013 'Bitstrips offer little creativity'. Retrieved from:

http://dailytrojan.com/2013/11/05/bitstrips-offer-little-creativity/ (accessed 5/6/17)

Clarke, V, Braun, V, \& Wooles, K 2015 'Thou shalt not covet another man? Exploring constructions of same-sex and different-sex infidelity using story completion'. Journal of Community \& Applied Social Psychology, vol. 25, no. 2, pp. 153-166.

Clarke, V \& Spence, K 2013, 'I am who I am'? Navigating norms and the importance of authenticity in lesbian and bisexual women's accounts of their appearance practices' Psychology \& Sexuality, vol. 4, no. 1, pp. 25-33.

Clarke, V \& Turner, K 2007, 'Clothes maketh the queer? Dress, appearance and the construction of gay, lesbian and bisexual identities', Feminism and Psychology, vol. 17, no. 2, pp. 267-276.

Clarke, V \& Smith, M., 2015, “Not hiding, not shouting, just me': Gay men negotiate their visual identities'. Journal of Homosexuality, vol. 62, no. 1, pp. 4-32.

Clarke, V, Hayfield, N, \& Huxley, C 2012, 'Lesbian, gay, bisexual and trans appearance and embodiment: A critical review of the psychological literature'. Psychology of Sexualities Review, vol. 3, no. 1, pp. 51-70.

Clarke, V, Hayfield, N, Moller, N, Tischner, I \& the Story Completion Research Group 2017 'Once upon a time...: Qualitative story completion methods', in V Braun, V Clarke, \& D Gray (eds.), Collecting qualitative data: a practical guide to textual, media and virtual techniques, Cambridge University Press, Cambridge, pp. 45-70.

Croce, M 2015 'Homonormative dynamics and the subversion of culture', European Journal of Social Theory, vol. 18, no. 1, pp. 3-20.

Eves, A 2004, 'Queer theory, butch/femme identities and lesbian space', Sexualities, vol. 7, no. 4, pp. 480-496.

Frith, H \& Gleeson, K 2004 'Clothing and embodiment: Men managing body image and appearance', Psychology of Men and Masculinity, vol. 5, no. 1, pp. 40-48.

Frith, H, 2013, 'Accounting for orgasmic absence: Exploring heterosex using the story completion method', Psychology and Sexuality, vol. 4, no. 3, pp. 310-322.

Frith, H, Riley, S, Archer, L \& Gleeson, K 2005, 'Editorial', Qualitative Research in Psychology, vol. 2, no. 3, pp. 187-198.

Gleeson, K 2011, 'Polytextual thematic analysis for visual data - pinning down the analytic' in P Reavey (ed.), Visual Methods in Psychology, Psychology Press, Sussex, pp. 314-329.

Gonzalez, CA \& Spencer, K 2015 'Femininity' in P Whelehan \& A Bolin, The international encyclopedia of human sexuality, Chichester, West Sussex, Wiley-Blackwell. Retrieved from http://search.credoreference.com.ezproxy.uwe.ac.uk/content/entry/wileyhs/femininity/0 
Goodings, L, Brown, D 2011, 'Textuality and visuality in myspace communication', in P Reavey (ed.), Visual Methods in Psychology, Psychology Press, Sussex, pp. 87-102.

Harper, D 2002, 'Talking about pictures: A case for photo elicitation', Visual studies, vol. 17 no. 1 , pp. 13-26.

Hayfield, N 2013, “"Never judge a book by its cover?": Students' understandings of lesbian, gay, and bisexual appearance', Psychology \& Sexuality, vol. 4, no. 1, pp. 16-24.

Hayfield, N, Clarke, V, Halliwell, E \& Malson, H 2013, 'Visible lesbians and invisible bisexuals: Appearance and visual identities among bisexual women', Women's Studies International Forum, vol. 40, no. 1, pp. 172-182.

Hayfield, N, Clarke, V \& Halliwell, E 2014, 'Bisexual women's understandings of social marginalisation: 'The heterosexuals don't understand us but nor do the lesbians", Feminism \& Psychology, vol. 24, no. 3, pp. 352-372.

Hayfield, N, Halliwell, E \& Clarke, V 2017, 'An exploration of bisexual, lesbian, and heterosexual women's body dissatisfaction, and body hair and make-up practices'. Psychology of Sexualities Review, vol. 8, no. 2, pp. 55-67.

Hurworth, R 2004, 'Photo-interviewing for research', Qualitative Research Journal, vol. 4 no. 1, pp. 73-79

Hutson, DJ 2010, 'Standing OUT/Fitting IN: Identity, appearance and authenticity in gay and lesbian communities', Symbolic Interaction, vol. 33, no. 2, pp. 213-233.

Huxley, C, Clarke, V \& Halliwell, E 2013, 'Resisting and conforming to the 'lesbian look': The importance of appearance norms for lesbian and bisexual women', Journal of Community and Applied Social Psychology, vol. 24, no. 3, pp. 205-219.

Jaramillo-Sierra, AL \& Allen, KR 2013, 'Who pays after the first date? Young men's discourses of the male-provider role'. Psychology of Men \& Masculinity, vol. 14, no. 4, pp.389-399.

Kitzinger, C \& Coyle, A 1995, Lesbian and gay couples: Speaking of difference. Psychologist, vol. $8 \mathrm{~m}$ no. 2, pp.64-69.

Kitzinger, C \& Powell, D 1995, 'Engendering infidelity: Essentialist and social constructionist readings of a story completion task', Feminism \& Psychology, vol. 5 no. 3, pp. 345-372.

Krakauer, ID \& Rose, SM 2002, 'The impact of group membership on lesbians' physical appearance', Journal of Lesbian Studies, vol. 6, no. 1, pp. 31-43.

Lamont, E 2017, "'We can write the scripts ourselves": Queer challenges to heteronormative courtship practices', Gender \& Society, vol. 31, no. 5, pp. 624-646.

Laner, M \& Ventrone, N 2000, 'Dating scripts revisited', Journal of Family Issues, vol. 21 no. 4, pp. 488-500.

Lever, J, Frederick, DA, \& Hertz, R 2015, 'Who pays for dates? Following versus challenging gender norms'. Sage Open, vol. 5, no. 4. 
Meadows, M 2007, 'I, avatar: The culture and consequences of having a second life', New Riders, Berkeley.

Monro, S 2015, 'Bisexuality: Identities, politics, and theories', Palgrave Macmillan, Basingstoke.

Nakamura, L 2002, 'Cybertypes: Race, ethnicity, and identity on the Internet, Routledge, London.

Nisa, F \& Al-Hafizh, M 2014, 'Teaching writing a narrative text by using comic creator (Bitstrips) as a medium to second grade students of junior high school', Journal of English Language Teaching, vol. 3 no. 1, pp. 72-77.

Pickens, C \& Braun, V 2018, "'Stroppy bitches who just need to learn how to settle?" Young single women and norms of femininity and heterosexuality, Sex Roles, vol. $x$, no. $x, p p . x x-x x$.

Pini, M, \& Walkerdine, V 2011, 'Girls on film: video diaries as autoethnographies' in P Reavey (ed.), Visual Methods in Psychology, Psychology Press, Sussex, pp. 139-152.

Pink, S 2015, 'Doing sensory ethnography', Sage, London.

Polhemus, T 2010, 'Street style', PYMCA, London.

Reavey, P 2010, 'Visual methods in psychology: Using and interpreting images in qualitative research', Routledge, London.

Riley, S, Brown, R, Griffin, C \& Morey, Y 2011, 'Tribal gatherings: using art to disseminate research on club culture' in P Reavey (ed.), Visual Methods in Psychology, Psychology Press, Sussex, pp. 190-204.

Roseneil, S, Crowhurst I, Hellesund, T, Santos, AC, \& Stoilova, M 2013 'Changing landscapes of heteronormativity: The regulation and normalization of same-sex sexualities in Europe'. Social Politics, vol. 20, no. 2, pp. 165-199.

Rothblum, ED 1994, 'Lesbians and physical appearance: Which model applies?' In B. Greene \& GM Herek (Eds.), Lesbian and gay psychology: Theory, research, and clinical applications (pp. 84-97). Thousand Oaks, California: Sage Publications Ltd.

Serapis, Z \& Boellstorff, T 2008, 'Coming of age in second life: An anthropologist explores the virtually human', Princeton, Princeton University Press.

Taylor, Y 2007, 'If your face doesn't fit...': The misrecognition of working-class lesbians in scene space', Leisure Studies, vol. 26, no. 2, pp. 161-178.

Taylor, Y 2008, 'That's not really my scene': Working-class lesbians in (and out of) place', Sexualities, vol. 11, no. 5, pp. 523-546. 
Tolman, DL Davis, BR \& Bowman, CP, 2016, "'That's just how it is": A gendered analysis of masculinity and femininity ideologies in adolescent girls' and boys' heterosexual relationships', Journal of Adolescent Research, vol. 31, no. 1, pp. 3-31.

Weeks, J Heaphy, B \& Donovan, C, 2001. Same sex intimacies: Families of choice and other life experiments, London, Routledge.

Wertz, JA 2014, 'Bitstrips and storybird: Writing development in a blended literacy camp', Voices from the Middle, vol. 21, no. 4, pp. 24-32.

Yancey, G \& Emerson, MO 2016, Does height matter? An examination of height preferences in romantic coupling. Journal of Family Issues, vol. 37, no. 1, pp. 53-73. 